\title{
MEDICALIZAÇÃO NO ENSINO SUPERIOR: O USO INDISCRIMINADO DE ANFETAMINAS POR ESTUDANTES DO CURSO DE MEDICINA
}

Lucas Messias Augusto de Sousa, Universidade Federal de Campina Grande (UFCG), lucas-augustosousa18@hotmail.com

Natália Bitu Pinto, Universidade Federal de Campina Grande (UFCG), nataliabitu@gmail.com

Rebeca Karollyne Rolim Ribeiro, Universidade Federal de Campina Grande (UFCG), rebeca.rrg@hotmail.com

\section{PALAVRAS-CHAVE: Medicalização; Anfetaminas; Impactos biopsicossociais.}

\section{INTRODUÇÃO}

A medicalização é um processo pelo qual o costume de vida é apropriado pela medicina e corrobora na construção de conceitos, hábitos e comportamentos sociais. Nesse raciocínio, situações ou acontecimentos antes tidos como comuns são transformados em quadros clínicos. Nessas ocasiões, é preciso desenvolver atos e ações destinadas à promoção, à qualidade de vida e à prevenção de doenças. Contudo, o que se sucede é o uso indiscriminado e em larga escala de medicamentos (CAPONI et al, 2010).

O fenômeno da medicalização ou da chamada automedicação, por abranger a vida cotidiana, faz parte do universo de muitos estudantes, sobretudo, naqueles que estão inseridos em um curso superior, contexto no qual as exigências, os níveis de estresse e a ansiedade se tornam intrínsecos. Especificamente os estudantes do curso de medicina, alvos deste estudo, por conviverem com a constante carga social e moral de sua futura carreira, formam um público de caráter autônomo no consumo de medicamentos estimulantes, dentre os quais se destacam as anfetaminas (LOPES apud AMARAL, 2014).

Essas substâncias psicoativas mudam o comportamento, a consciência, o humor e a cognição, atuando no sistema nervoso central. Suscitam como agente apaziguador das adversidades psíquicas, apesar de não atuarem nas causas ou auxiliarem os usuários em seus pensamentos e na resolução de seus anseios (PICOLOTTO et al, 2010). 
O aumento do consumo indiscriminado de medicamentos psicoativos é, pois, um problema que gera consequências assoladoras à sociedade, sobrelevando-se seus impactos biopsicossociais, que o qualifica como importante problema de saúde pública, principalmente entre os jovens.

\section{METODOLOGIA}

Trata-se de uma revisão bibliográfica, de caráter dissertativo, realizada com a pesquisa de fontes acerca da medicalização autônoma de anfetaminas por parte dos estudantes de medicina. A pesquisa foi iniciada no mês de julho de 2017. Sendo feita a dissertação sobre a composição das anfetaminas, os fatores que regem a automedicação, as circunstâncias cognitivas dos estudantes em nível superior e as implicações do uso de substâncias psicoativas por estudantes de medicina. Houve problemas nos percursos de indexação nas bases de dados bibliográficas; para tanto, optou-se pela busca por termos livres, sem um real uso de descritores. Foram selecionados artigos científicos publicados desde 1998 até anos mais recentes, para uma efetivação sem qualquer exclusão de pesquisas já publicadas. Sendo incluídos artigos escritos somente em português. Todos os arquivos foram pesquisados em plataformas de busca acadêmica como o Scielo, Scholar Google, Bireme, Lilacs e periódico CAPES.

O presente estudo não necessitou ser submetido ao Comitê de Ética em Pesquisa (CEP) por utilizar, exclusivamente, informações coletadas de bases de dados online.

\section{RESULTADOS E DISCUSSÕES}

O processo de "medicalização da vida" se respalda na transformação de eventos tidos como normais da existência humana em objetos de análise por profissionais de saúde, por meio da qual fazem uso de uma diversidade de medicamentos e equipamentos. Sendo assim, situações habituais da diversidade humana são incorporadas na óptica do que é definido como sendo patológico. (CAPONI et al, 2010)

Os autores ainda afirmam que esse fenômeno, ao contrário do que possa parecer, não apresenta um histórico recente, uma vez que vem sendo incorporado no aspecto social há mais de dois séculos. Com a ascensão da medicina, obteve-se como efeito uma vida cotidiana em que o cidadão passa a ter familiaridade com as práticas e os conceitos difundidos. Desse 
modo, o indivíduo passa a conceber a saúde como princípio vital, tornando-se capaz de não medir esforços na tentativa de preservá-la.

Rosana I. dos Santos e Mareni R. Farias (2010) analisam o papel sócio-cultural que a medicalização desempenha, afirmando que as banalizações dos medicamentos aliadas ao viés da hiperprevenção direcionam essas soluções farmacológicas à concepção de que são "amortecedores químicos" frente às conjunturas cotidianas de impasses subjetivos e sociais. Consequentemente, fármacos de uso discutível são extensivamente usados sem a devida comprovação científica e equiparação de benefícios.

Nessa perspectiva, convém ressaltar que a medicalização no curso superior é um fenômeno bastante comum entre a maioria dos estudantes. Segundo um estudo sobre automedicação em estudantes do segundo ano de enfermagem e medicina e moradores do bairro Vila Nova, mostrou que uma parcela igualmente parecida de estudantes, cerca de $36,5 \%$, não se aconselhavam com o profissional farmacêutico no que tange à aquisição de uma droga medicamentosa. (LOPES apud AMARAL, 2014)

Considerando que a automedicação está infimamente ligada ao teor de conhecimento científico, vários estudos brasileiros concluem que os maiores adeptos dessa concepção são aqueles que dispõem de um grau maior de conhecimento. (GUSHIKEN, 2013) Assim, os estudantes universitários formam uma comunidade bastante jovem e saudável, mesmo os seus problemas de saúde e o tipo específico de medicamento com alto grau de consumo não refletem os da população comum. Contudo, esse grupo está exposto a fatores de riscos peculiares, como o estresse e o esforço intelectual intenso, cujas consequências na saúde são relevantes. (LOPES apud AMARAL, 2014)

Aliados a esses fatores psicológicos, correm paralelo os elevados índices de suicídio encontrados nos estudantes de medicina como também nos médicos já atuantes, causados ou corroborados pela perda da onipotência que a profissão é inserida, o medo constante de falhar e a virilidade idealizada por muitos que desejam seguir a carreira médica durante o curso e a vida profissional. (MELEIRO, 1998)

Diagnosticando esta parte de estudantes imiscuídos no desejo de sempre se manterem nas exigências que a carreira médica exige, propõem-se a perpetuar a prática da 
automedicação como forma de alívio às adversidades com as quais se deparam. Por conseguinte, o uso de anfetaminas, como o metilfenidato, torna-se importante suporte no que tange à ação de potencialização do desempenho cognitivo, principalmente no período de avaliações, cuja sobrecarrega com vasto conteúdo é indissociável.

As anfetaminas estão inseridas no grupo de substâncias psicoativas (SPA) e têm sido alvo de pesquisas devido à alarmante intensificação do seu uso e os devidos impactos sócioeconômicos, bem como os efeitos na saúde pública. (LUCAS et al, 2006)

Essas substâncias psicotrópicas, quando utilizadas, são vistas como fonte para a propulsão de sensações e emoções gratificantes. PICOLOTTO et al (2010) sugerem que as SPA surgem como um extremo aliviador das diversidades psíquicas, uma vez que quem as utiliza busca uma alternativa de focar a atenção, assim como aprimorar o desempenho acadêmico.

Nesse contexto, as anfetaminas são caracterizadas como sendo substâncias simpatomiméticas cuja ação evidenciada é predominante no sistema nervoso central. Seu mecanismo de ação indica a liberação de dopamina, bem como a dispensa de outros neurotransmissores, tais como serotonina e noradrenalina, a partir dos quais ocorre inibição da sua recaptação no terminal axônico pré-sináptico. Essa distribuição, pois, explica os efeitos farmacológicos e tóxicos derivados do uso desses elementos. (SULZER et al., 2005; GOODMAN; GILMAN, 2010).

As anfetaminas são apressadamente absorvidas no trato gastrointestinal. Em seguida, penetram livremente pela barreira hematoencefálica, causando os efeitos ao sistema nervoso central. Além disso, são rapidamente absorvidas pela mucosa nasal. Assim sendo, são distribuídas em grande parte dos tecidos do organismo humano (RANG et al, 2001).

A administração de estimulantes como a anfetamina têm como efeito biológico o aumento de dopamina na fenda sináptica que é posteriormente seguido, de forma pragmática, de mecanismos compensatórios estimulados por retroalimentação negativa que buscam diminuir a quantidade de dopamina na fenda. Aliado a isso, a ingestão de anfetaminas acarreta no fato de que a reação a estímulos gustativos palatáveis e a sensibilidade ao reforço têm, 
como meio comum, a capacidade de ativar o sistema dopaminérgico mesolímbico. (SILVA et al, 2001).

As anfetaminas agem provavelmente sobre a formação reticular e reproduzem adicionalmente a ação do sistema nervoso simpático, provocando taquicardia e nervosismo. A formação reticular do SN é responsável pela coordenação de grande número de funções autônomas vegetativas: respiração, deglutição, pressão sanguiínea e termorregulação. Agindo sobre essa região, as anfetaminas acabam estimulando ainda os centros nervosos superiores, mantendo-os em estado de vigilância e vigília (ZEFERINO, 2004).

Segundo a mesma autora, as drogas estimulantes do tipo anfetaminas aumentam a produção de dopamina e noradrenalina, pois possuem uma conformidade química biologicamente parecida, o que acaba gerando sintomas e efeitos centrais do tipo psicoestimulante, tais como estado de alerta persistente, com diminuição do sono, elevação do estado de ânimo, aumento da atividade motora, menor sensação de fadiga e diminuição do apetite. Além disso, provocam efeitos periféricos semelhantes aos determinados pela estimulação do sistema simpático, tais como aceleração dos batimentos cardíacos e aumento da pressão sangüínea arterial, sendo por isso classificada entre as aminas simpatomiméticas. Como consequiência destas ações, tem-se aumento da concentração das catecolaminas o que resulta numa ação hipertensora, taquicardizante, broncodilatadora e midriática.

Como efeito, o uso incorreto ou ilegal de medicamentos à base de anfetaminas acaba por inserir aqueles que o pratica em um ambiente instável de reações biológicas adversas. Sendo agentes simpatomiméticos, as anfetaminas possuem ações e efeitos resultantes da estimulação de receptores alfa e beta. Seus efeitos variam conforme a dosagem e o organismo do usuário, abrangendo problemas cardiovasculares acentuados, o aumento de pressão sanguínea (PA) e a redução da frequência cardíaca. Não obstante, uma maior dosagem indiscriminada, apresenta como consequência o surgimento de taquicardias e arritmias. (SILVA, 2002)

Relacionados a problemas adversos psicossociais, o uso incorreto de anfetaminas gera aumento de atividade locomotora resultante do sistema dopaminérgico mesolímbico e também reações comportamentais, dentre as quais se destacam: fungar, morder, ranger de dentes, movimentos de perna e cabeça incomuns. Além disso, em alguns usuários ocorre o 
risco de irritabilidade e agressividade, com resposta de fuga, defesa ou isolamento. (MARCON apud SILVA, 2002)

Por terem melhor conhecimento científico, até mesmo acerca das ações negativas das anfetaminas, estudantes de medicina acabam modulando sua vida acadêmica pelos fármacos, independente de orientações ou mesmo avaliação diagnóstica cuidadosa e monitoramento contínuo.

O descobrimento dos efeitos de fármacos estimulantes, principalmente anfetaminas, se tornou uma esperança promissora para problemas de comportamento e de delinquência, TDAH, entre outros. (MARCON, 2012) Contudo, o tratamento biológico promissor para esses transtornos, sugere aos estudantes de medicina a escolha preferível comum para o uso indiscriminado da droga, como o metilfenidato, sem qualquer preocupação com seus efeitos.

Evidencia-se, portanto, que conhecer o padrão do consumo de substâncias psicoativas de determinada população é essencial à implantação de programas de prevenção ao consumo, principalmente para combater o uso indiscriminado de medicamentos e a automedicação.

Profissionais de saúde e a população, por seu turno devem ficar alerta e exercer seu espírito crítico ao atentar até que ponto as novas tecnologias poderão atuar como alternativa de controle da vida com o objetivo primordial de solucionar os paradoxos da existência humana.

\section{CONSIDERAÇÕES FINAIS}

Diante do exposto, a medicalização da vida surge como cerne no que diz respeito a todo tipo de problemática da saúde a partir da concepção autônoma dos indivíduos. Dentre estes, em especial os que possuem algum conhecimento científico, como o grupo dos estudantes de medicina. Essa atitude nutre apenas as querelas biológicas, sem uma efetiva necessidade do diagnóstico médico ou sem o embasamento adequado acerca dos efeitos colaterais.

Nesse sentido, relativo ao espectro dos impactos biopsicossociais provocados pelo uso indiscriminado de substâncias psicoativas, como as anfetaminas, faz-se necessário a atitude reflexiva acerca da motivação por esse tipo de solução farmacológica. 
Sendo assim, é imprescindível ressaltar o desafio de pensar em que condições a medicalização poderia ou não ser justificável. É necessário entender as doenças psicoativas como problemas que devem ser enfrentados com o auxílio e cuidados profissionais. A medicalização surge, hoje, como um atrativo que possibilita o amparo biológico a enfermidades mentais. $\mathrm{O}$ uso incorreto, como solução para processos psicossociais, afeta tanto a saúde mental como física. Espera-se, portanto, que novas pesquisas atuem no desenvolvimento de práticas efetivas do cuidado à saúde que não abstenham à simples extensão cada vez maior de um mercado de consumidores cativos, mas sim, a uma abordagem terapêutica aliada a uma intervenção comunicativa do usuário, que possibilite seu entendimento sobre os riscos que pode estar inserido e um esclarecimento de ações curativas diversas para as suas dificuldades cognitivas.

\section{REFERÊNCIAS}

CAMARGO JR, K. R. Medicalização, farmacologização e imperialismo sanitário. Cadernos de Saúde Pública, Rio de Janeiro, v.29, n.5, p. 844-846, May, 2013.

CAPONI, S.; VERDI, M.; BRZOZOWSKI, F. S.; HELLMANN, F. Medicalização da Vida: Ética, Saúde Pública e Indústria Farmacêutica. 1 ed. Palhoça: Editora Unisul, 2010.

CARNEIRO, S. G. et al. O uso não prescrito de metilfenidato entre acadêmicos de Medicina. Cadernos UniFOA, v. 8, n. 1 (Esp.), p. 53-59, May, 2013.

GOODMAN, L. S.; GILMAN, A. As bases farmacológicas da terapêutica. Rio de Janeiro: McGrawHill, 2010.

GONÇALVES, H. C. B.; FERREIRA, R. G. F.; Os psicofármacos como uma necessidade temporal da atualidade: uma perspectiva psicológica. Fractal: Revista de Psicologia, Rio de Janeiro, v.20, n.02, p. 641-642, July./Dec., 2008.

GUSHIKEN, V. O.; HAYASHIDA, M. N.; MELETTI, J. F. A. Automedicação em estudantes de medicina. Perspectivas Médicas, v. 24, n. 1, p.10-19, Jan./Jun., 2013. 
LOPES, W. F. L. et al. A prática da automedicação entre estudantes de uma instituição de ensino superior de Teresina-PI. Revista Interdisciplinar, Teresina, v. 7, n. 1, p. 17-24, jan./ fev./mar., 2014.

LUCAS, A. C. S. et al. Uso de psicotrópicos entre universitários da área da saúde da Universidade Federal do Amazonas, Brasil. Cadernos de Saúde Pública, Rio de Janeiro, v.22, n.03, Mar., 2006.

MARCON, C. et al. Uso de anfetaminas e substâncias relacionadas na sociedade contemporânea. DisciplinarumScientia| Saúde, Santa Maria, v. 13, n. 2, p. 247-263, 2012.

MELEIRO, A. M. A. S. Suicídio entre médicos e estudantes de medicina. Revista da Associação Médica Brasileira, São Paulo, v. 44, n. 2, p. 135-140, June,1998.

PICOLOTTO, E. et al. Prevalência e fatores associados com o consumo de substâncias psicoativas por acadêmicos de enfermagem da Universidade de Passo Fundo. Ciência \& Saúde Coletiva, Rio de Janeiro, v.15, n.03, May., 2010.

RANG, H. P.; DALE, M. M.; RITTER, J. M. Farmacologia. 4 ed. São Paulo: Guanabara Koogan, p. 508-510, 2001.

SILVA, M. T. A. et al. Análise funcional da dependência de drogas. Sobre comportamento e cognição, p. 422-442, 2001.

SILVA, P. Farmacologia. 6. ed. Rio de Janeiro: Guanabara Koogan, 2002, 1374p

SULZER, S. et al. Mechanisms of neurotransmitter by amphetamines: A review. Progress in Neurobiology, New York, v. 75, p. 406-433, 2005.

ZEFERINO, M. T. Acidentes de trânsito e os estimulantes do tipo anfetaminas: estudo de caso junto às empresas de transporte rodoviário de cargas no estado de Santa Catarina. 2004. 143 f. Dissertação (Mestrado em Engenharia Civil) - Centro Tecnológico, Universidade Federal de Santa Catarina, Florianópolis, 2004. 